\title{
The Architectural Surfaces Characteristics of Sandy Braided River Reservoirs, Case Study in Gudong Oil Field, China
}

\author{
Xixin Wang $\left(D,{ }^{1}\right.$ Fan Zhang $\left(\mathbb{D},{ }^{1}\right.$ Shaohua Li $\left(\mathbb{D},{ }^{1}\right.$ Luxing Dou $\left(\mathbb{D},{ }^{2}\right.$ Yuming Liu $\left(\mathbb{D},{ }^{2}\right.$ \\ Xiaoxu Ren (iD, ${ }^{2}$ Depo Chen $\left(\mathbb{D},{ }^{3}\right.$ and Wen Zhao ${ }^{4}{ }^{4}$ \\ ${ }^{1}$ Key Laboratory of Exploration Technologies for Oil and Gas Resources (Yangtze University), Ministry of Education, \\ Wuhan 430100, China \\ ${ }^{2}$ College of Geoscience, China University of Petroleum, Beijing 102249, China \\ ${ }^{3}$ Geological Science Research Institute of Shengli Oilfield, SINOPEC, Dongying 257061, China \\ ${ }^{4}$ China Petrochemical Press, Beijing 100011, China
}

Correspondence should be addressed to Shaohua Li; 534354156@qq.com and Luxing Dou; douluxing@hotmail.com

Received 7 September 2020; Revised 17 November 2020; Accepted 29 March 2021; Published 30 April 2021

Academic Editor: Constantinos Loupasakis

Copyright (c) 2021 Xixin Wang et al. This is an open access article distributed under the Creative Commons Attribution License, which permits unrestricted use, distribution, and reproduction in any medium, provided the original work is properly cited.

\begin{abstract}
The architecture analysis of the different orders sedimentary bodies is of great significance to the efficient development of oil and gas fields. In order to investigate the effects of the architectural interfaces on reservoir quality and heterogeneity, this study takes the Gudong oil field as a case to investigate the architectural characteristics of hierarchical bounding surfaces using detailed descriptions of core and wireline logs. Architectural models from the 7th-order to the 3rd-order are analyzed, and the developmental characteristics of the 5th-order braided river, 4th-order single sandstone, and 3rd-order accretion are summarized. The interlayer between two braided rivers is floodplain mud deposition, with poor physical properties, stable thickness, and strong blocking capacity. Two models of interlayers are found in the 4th-order deposition. The first interlayer is between the braided filling channel and midchannel bar, which is composed of generally fine-grained sediments with calcium cementation and poor physical properties. The second interlayer is a transformation belt between two midchannel bars and is generally composed of gravel-scoured deposition with penetration capability. The 3rd-order surfaces are defined as the surfaces of accretions within midchannel bars. Two models of interlayers are also found in the 3rd-order surfaces of accretions. The paleocurrent of the sandy braided river is reconstructed by synthesizing the core data, well logging data, and production performance data. A total of 1 fluvial system (7th-order), 2 compound braided rivers (6th-order), 11 braided rivers (5th-order), 41 midchannel bars (4th-order), and 96 accretions (3rd-order) are developed in the study area.
\end{abstract}

\section{Introduction}

Fluvial reservoirs are one of the main clastic reservoirs [14], whose petroleum resources account for $42.6 \%$ of China's total exploitation [5]. Sandy braided river reservoirs, which are an important type of fluvial reservoirs, have been extensively studied by scholars [6-9]. A frequent-diversion braided river has a so-called "special wandering" characteristic, in which the sand bodies interact with one another by cutting and superposing although they are continuously distributed and disconnected [1012]. Therefore, braided river reservoir should be analyzed architecturally [13-15]).
Many scholars have carried out a series of researches on braided rivers through the observation of modern deposits and outcrops. Yu et al. [14] studied the braided river outcrop section and systematically described the sedimentary characteristics, lithofacies association, hierarchical interface, and sedimentary model of braided river reservoir. Jin et al. [16] divided the channel sand bodies into three types, which include superimposed, lateral, and isolated. Rucsandr (2001) applied GPR technology, core, and outcrop studies to dissect fluvial sand bodies. The radar profile is used to divide the reservoir architecture units.

The architectural analysis mainly includes two aspects: (1) the spatial contact relation and internal structure of 
architectural elements and (2) the distribution law and development characteristics of architectural bounding surfaces [17-19]. The architectural element analysis of reservoirs and sedimentary architectural patterns of sandy braided rivers have currently achieved certain successes [2, 20-23]. However, the sedimentary structural characteristics, architectural pattern, and hierarchical interfaces characteristics of braided river reservoirs have not been systematically studied due to the complexity and diversity of cutting and superposing relationships for underground reservoirs [14, 24, 25].

Likewise, the paleocurrent reconstruction of underground reservoirs in dense well-network pattern areas has not been attempted $([26,27][28])$. Thus, the sedimentary characteristics of architectural elements and hierarchical bounding surfaces are systematically analyzed, and the channel and barform architecture of a sandy braided river is reconstructed using Miall's classification method for the hierarchical architecture of fluvial channels combined with the core data, well logging data, and dynamic data of dense drilling well areas. The architectural characteristics of underground reservoirs should be investigated due to their important theoretical significance in exploration and exploitation.

In this paper, sedimentary environment and sedimentary characteristics were studied by core description and analysis. The architecture interface and architecture units were identified using wireline logs, and the characteristics of different architecture units are further analyzed. Finally, the direction of the paleocurrent was determined.

\section{Geological Setting}

The Gudong oil field is a near-north-south-trend anticline structural reservoir in the northeastern part of the Jiyang Depression and the northern edge of the Yellow River estuary in eastern China (Figure 1). The reservoir is mainly composed of loose sandstones from the Paleogene Guantao Formation. At the end of the Paleogene, the Jiyang Depression was lifted by the Dongying movement, thereby stripping and flattening the top of the Dongying Formation. During the Neogene, the Guantao Formation began to develop extensive fluvial deposits due to the height difference, abundant provenance, and braided river development. Then, the terrain height difference became small, and the sedimentary environment gradually shifted from braided to the meandering river when the upper section of the Guantao Formation began to deposit. The main oil-bearing formation is the upper section of the Guantao Formation. In this study, the $6^{3+4}$ layer of the Guantao Formation from the Neogene is used as an example; this reservoir has high porosity and permeability, and its buried depth is $1220-1340 \mathrm{~m}$ (Figure 2).

The dense well areas are in the east wing of the Gudong oil field. The north, west, and south sides are bounded by faults. The terrain slope is gentle, and the dip angle is generally less than $3^{\circ}$. The study area has 355 wells, which mainly use the antinine point well pattern and have approximate distances between wells of 30-150 m. Furthermore, 6 sealed coring wells and 3 tracer monitoring test well groups covering 31 injection and production wells are situated in the study area.

\section{Methods}

A total of 355 drilling wells and 6 coring wells are found in the dense well pattern area. All drilling wells have conventional logging curves with spontaneous-potential (SP), Gamma (GR), caliper log (CAL), sonic (AC), neutron (CNL), density (DEN), true resistivity (RT), and induced conductivity (COND). From the coring wells, we use 100 samples for performing several tests, such as granularity analysis, porosity and permeability analysis, rock thin section, scanning electron microscope, and conventional mercury injection test.

Various scaled architectural elements and the hierarchical bounding surfaces are identified and classified refinedly by observing the cored-well, single-well recognition, and interwell prediction of dense well pattern area ( $\mathrm{Li}$ et al., 2011; [16, 29]). The 7th-order to 3rd-order architectural models are analyzed, and the developmental characteristics of the 5th-order braided river, the 4 th-order single sandstone (single midchannel bar and single-braided filling channel), and 3rd-order accretion are summarized by using Miall's classification method of architectural elements and hierarchical bounding surfaces.

The lithofacies variation of various scaled architectural elements and hierarchy of bounding surfaces are summarized, and the genetic mechanism of the hierarchical bounding surfaces is analyzed based on the cored-well data. The penetration capabilities of various hierarchical bounding surfaces are compared according to the physical properties of reservoirs obtained in an analytical laboratory test.

The well logging and production performance data of the dense well pattern area are synthesized to reconstruct the paleocurrent of the sandy braided river in the west 7 th block of the Gudong oil field.

\section{Results}

4.1. Sedimentary Environment. The core scan photos of 27J234, 28-J266, 28-J255, 29-J254, 29-J246, and 29-J266 (Figure 3) show horizontal, parallel, tabular cross-, wavy cross-, and trough cross-beddings, and scoured surfaces are developed in the study area. These features are typical sedimentary structures of fluvial facies. Wavy, trough, and tabular cross-beddings are typical characteristics of midchannel bars in braided rivers. Meanwhile, horizontal bedding is generally developed in braided filling channel microfacies.

In the 29-J254 coring example, the sample points $6^{31}, 6^{32}$, $6^{41}$, and $6^{42}$ are considered the cumulative probability curve and $\mathrm{C}-\mathrm{M}$ diagram (Figure 4 ). The particle size probability curve and C-M diagram show that the cumulative curve of grain size probability comprises two steps. The overall suspension of the upper and lower parts of the overall jump passes the overall slope of line 70-80, thus reflecting good sorting; on the $\mathrm{C}-\mathrm{M}$ diagram, the sample points are mainly concentrated in the QR section, thereby showing positive rhythm characteristics of the river and onshore tractive current. In summary, the Guan $6^{3+4}$ position has an irregular binary structure, and the underlying sand deposits are thick. 


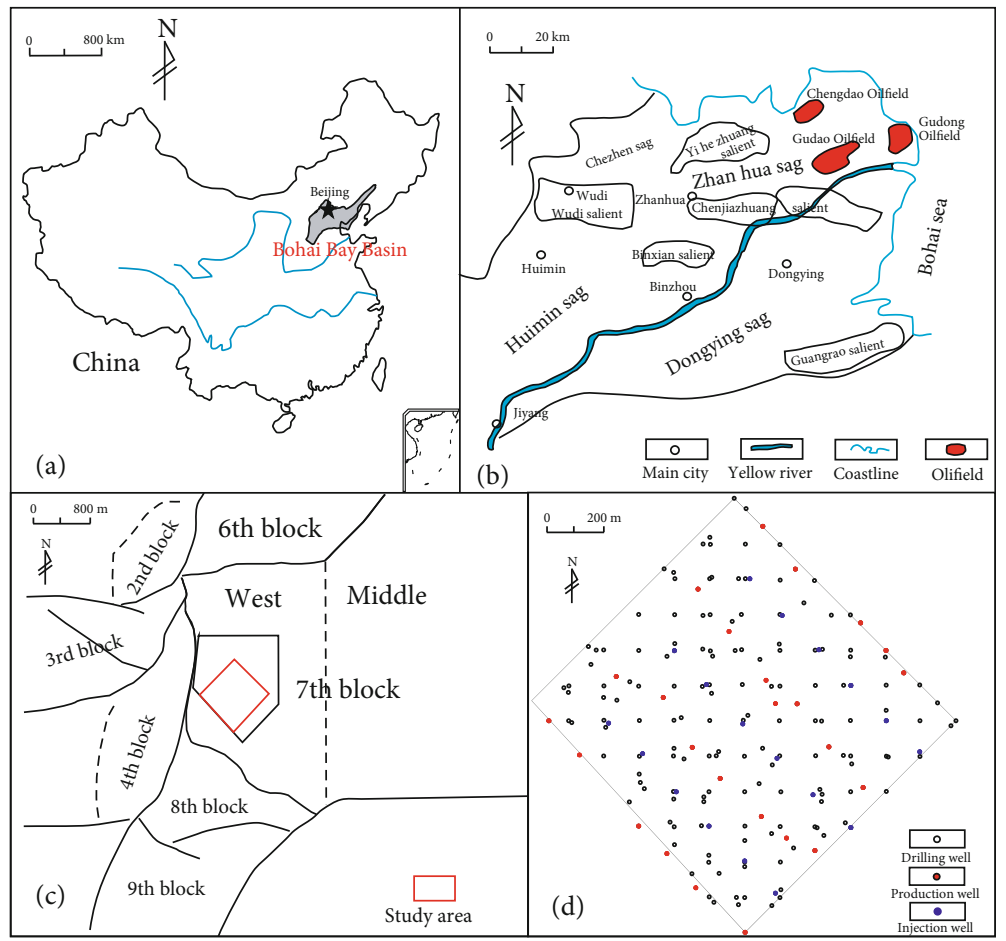

FIGURE 1: (a) Bohai Bay Basin. (b) Jiyang Depression. (c) Gudong oilfield and the location of the study area. (d) The distribution of wells in the study area.

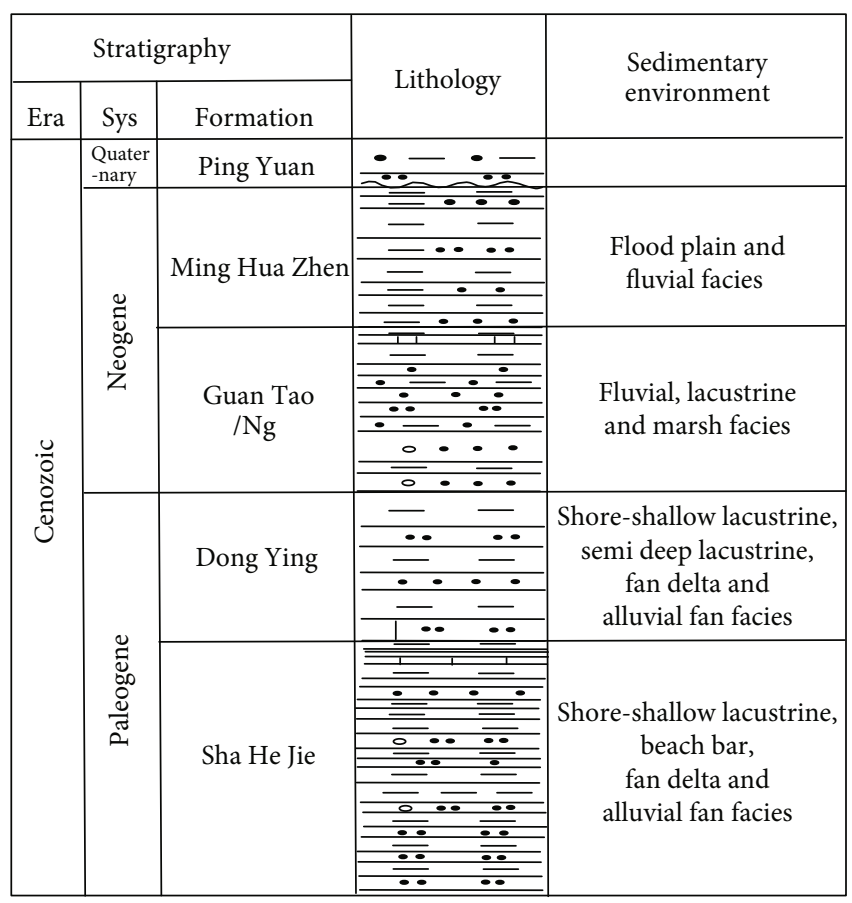

\begin{tabular}{ll}
\hline$-\rightarrow$ Mudstone & Sandstone \\
$\ldots$ G. Gravelly sandstone &
\end{tabular}

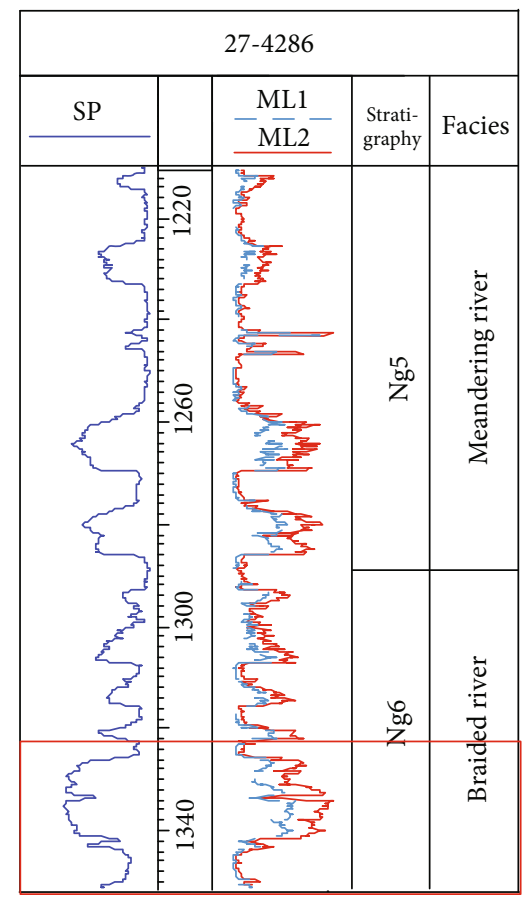

FIgURE 2: Characteristics of Stratigraphy and Sedimentary environment. Sp: spontaneous-potential; ML: microlaterolog.
The study area has the same characteristics as a typical sandy braided river and is subdivided into braided filling channel, midchannel bar, and floodplain microfacies. Guan $6^{3}$ is mainly composed of the braided filling channel and floodplain deposits, and Guan $6^{4}$ mainly has the midchannel bar sedimentary microfacies. 


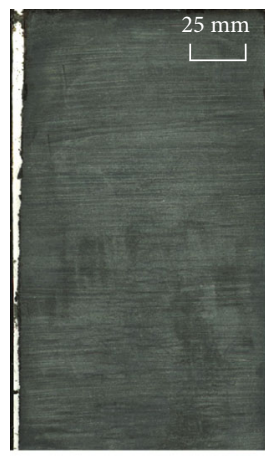

(a)

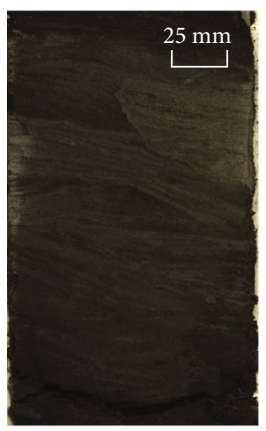

(g)

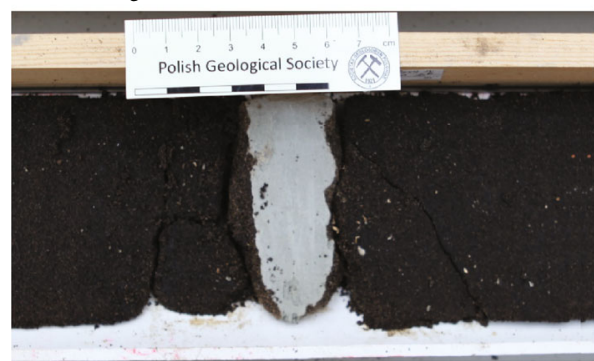

(l)

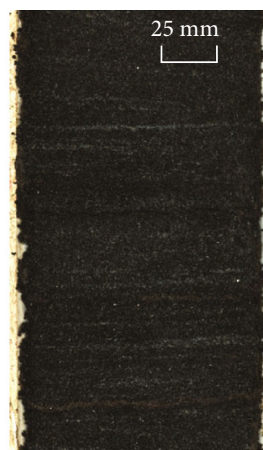

(b)

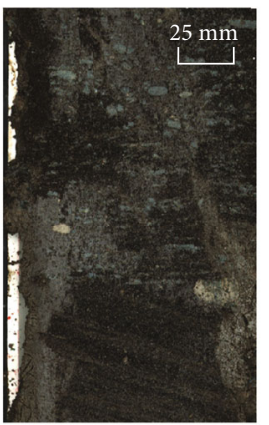

(h)

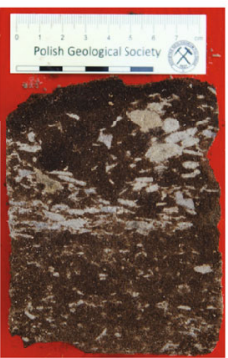

(m)

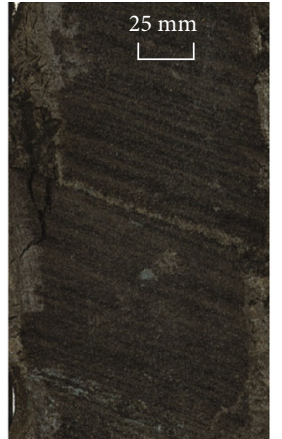

(d)
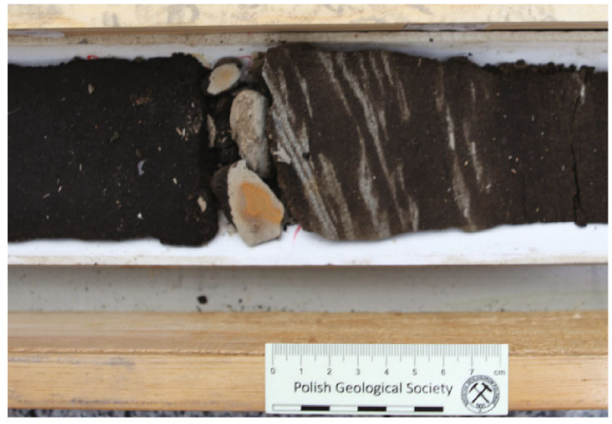

(i)

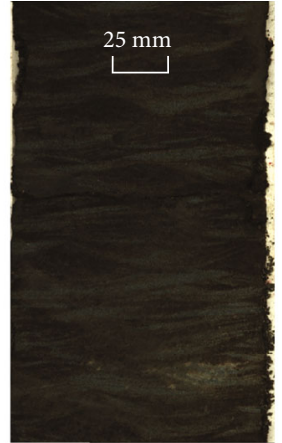

(e)

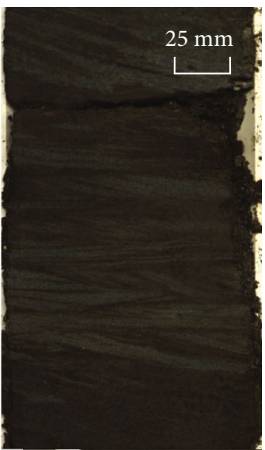

(f)

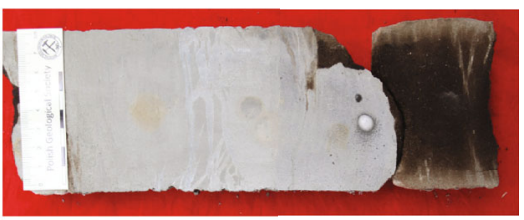

(j)

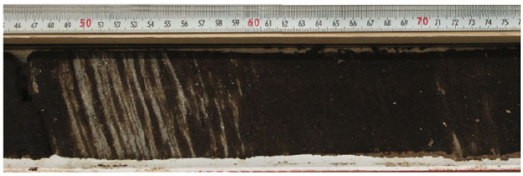

(k)

FIgURe 3: Core photos of Sedimentary structure in Guan6 ${ }^{4}$ : (a-h) core scan photos; (i-o) core photos. (a) Well 29-J246, 1287.20 m, green muddy siltstone, horizontal bedding. (b) Well 29-J246, $1337.90 \mathrm{~m}$, dust middle-fine-grained sandstone, parallel bedding. (c) Well 29-J254, $1287.1 \mathrm{~m}$, celadon middle-fine-grained sandstone, low-angle oblique bedding. (d) Well 29-J246, $1334 \mathrm{~m}$, dust middle-fine-grained sandstone, high-angle oblique bedding. (e) Well 29-J254, $1286.7 \mathrm{~m}$, celadon fine-grained sandstone, wavy cross-bedding. (f) Well 29-J254, $1286.9 \mathrm{~m}$, celadon fine-grained sandstone, trough cross-bedding. (g) Well 29-J254, celadon middle-fine-grained sandstone, trough crossbedding. (h) Well 29-J246, $1333.80 \mathrm{~m}$, celadon mud pebble middle grained sandstone, scouring surface. (i) Well 29-J254, mud gravel sandstone, gravel-scouring surface deposition. (j) Well 29-J254, bottom of braided filling channel, calcium cementation, argillaceous siltstone. (k) Well 29-J254, fine-grained deposition with mud stripes. (l) Fine-grained deposition, fall silt seam. (m) Well 26-J286, suspending mud gravel deposition. (n) Scouring eroded channel surface. (o) Well 29-J254, irregular binary structure (thin mud at the top and thick sandstone at the bottom).

4.2. Architectural elements. The sedimentary environment of the study area is a typical sandy braided river. The braided river is divided into 5th-order braided river, 4 th-order single sandstone (single midchannel bar and single-braided filling channel sand bodies), and 3rd-order accretion, as categorized by Miall's classification of fluvial architecture. This study focuses on the 4 th-order architectural elements. The main 4th-order architectural elements are the midchannel bar and braided filling channel. Based on core description and logging data, seven kinds of midchannel bar deposits and four kinds of braided filling channel deposits are identified (Figure 5).

The midchannel bar mainly consists of box, compound box, gearbox, high-amplitude bell type, compound bell, com- pound round, and funnel types. Fine sandstones dominate the box type, and the SP and COND curves show a single box-like shape with a high amplitude, a thickness of $4 \sim 8 \mathrm{~m}$, and a ratio of $41.8 \%$ for the seven types. In the compound box type, the interlayer of the silty mudstone can be found in fine-sand sandstones. The curve shows many sets of box features; the amplitude is high, the thickness is larger than the box shape, which is $4 \sim 13 \mathrm{~m}$, and the proportion is $22.9 \%$. The gearbox profile is in the shape of a box. However, the SP has a tooth-like shape and has a noticeable return, thus reflecting the apparent distribution of the silty mudstone interlayer, which accounts for approximately $5.5 \%$ of all types. In the high-amplitude bell type, where the lower part is fine sandstone and the upper part is siltstone (silty 

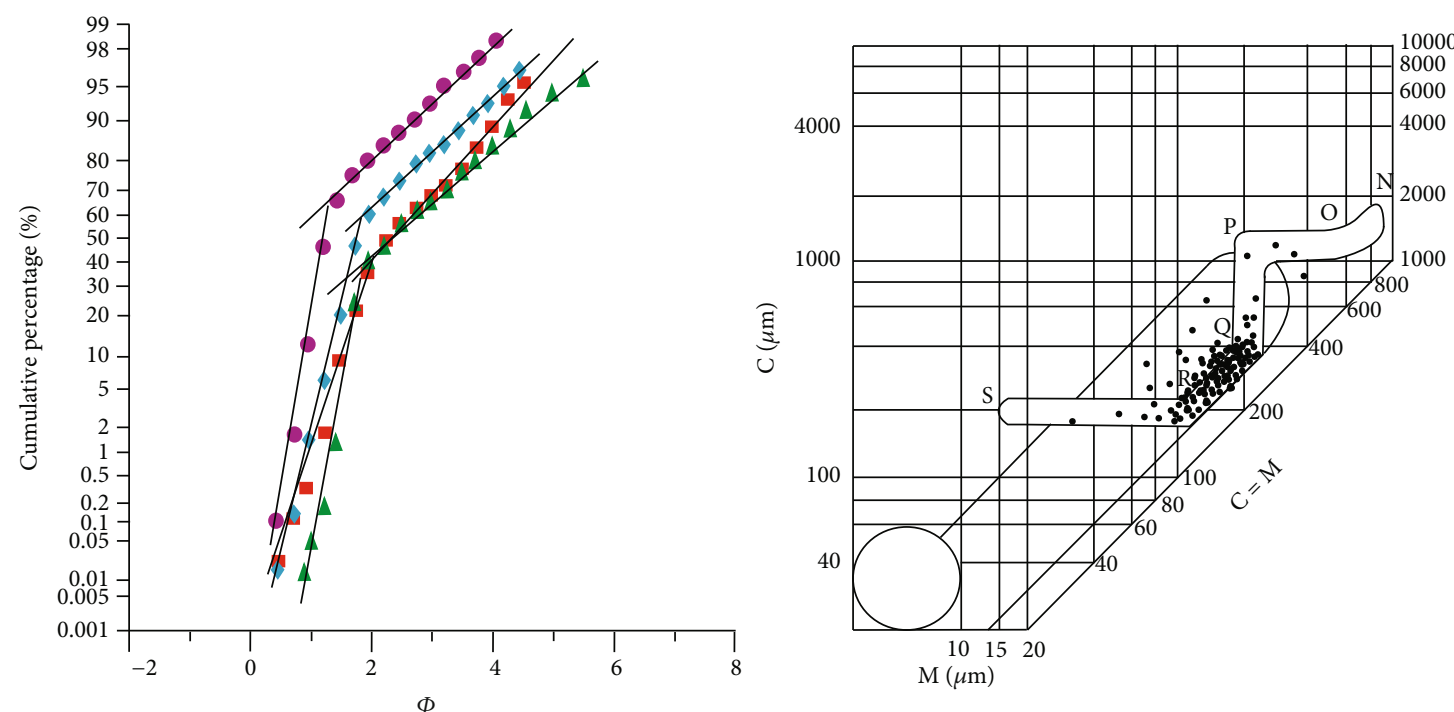

- $631: 1317.4-1317.5 \mathrm{~m} \quad \boldsymbol{\Delta} 641: 1325.5-1325.74 \mathrm{~m}$

FIgURE 4: Grain size probability curve and C-M diagram.

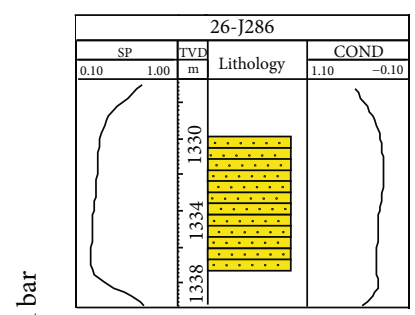

(a) Box type

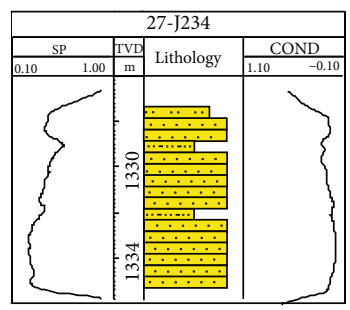

(e) Compound bell type

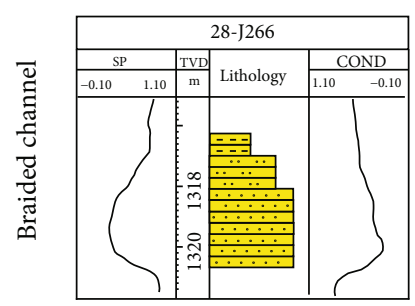

(a) Sand filling

$\because \because{ }^{\prime}$ Fine sandstone

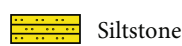

Si.........: Silty mudstone

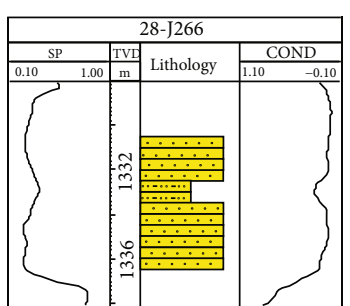

(b) Compound box type

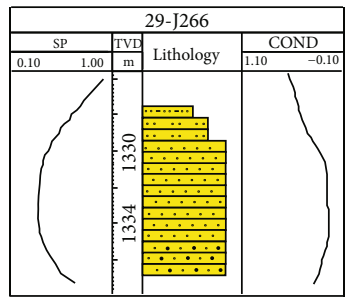

(f) Compound round type

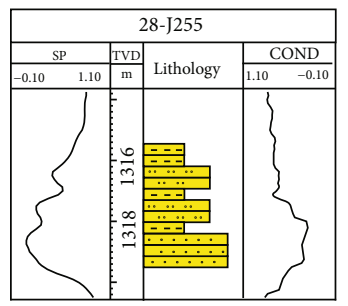

(a) Sand mixed with mud filling

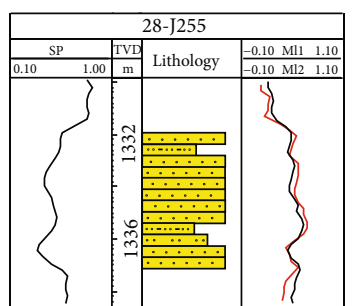

(c) Gear box type

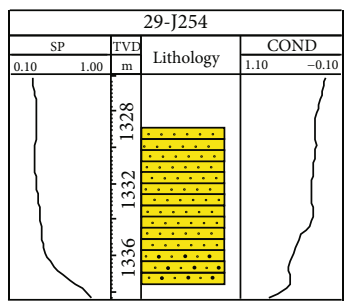

(g) Funnel type

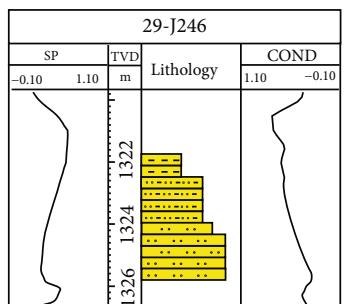

(c) Sand at bottom and mud at top filling

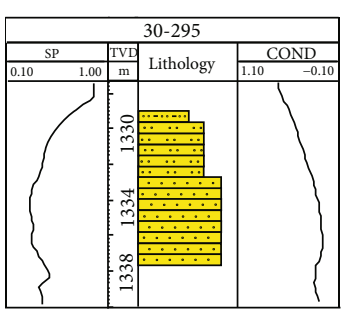

(d) High amplitude bell type

$\because \cdots$ Gravel sandstone

Mudstone

FIgure 5: Types of midchannel bar and braided filling channel. 

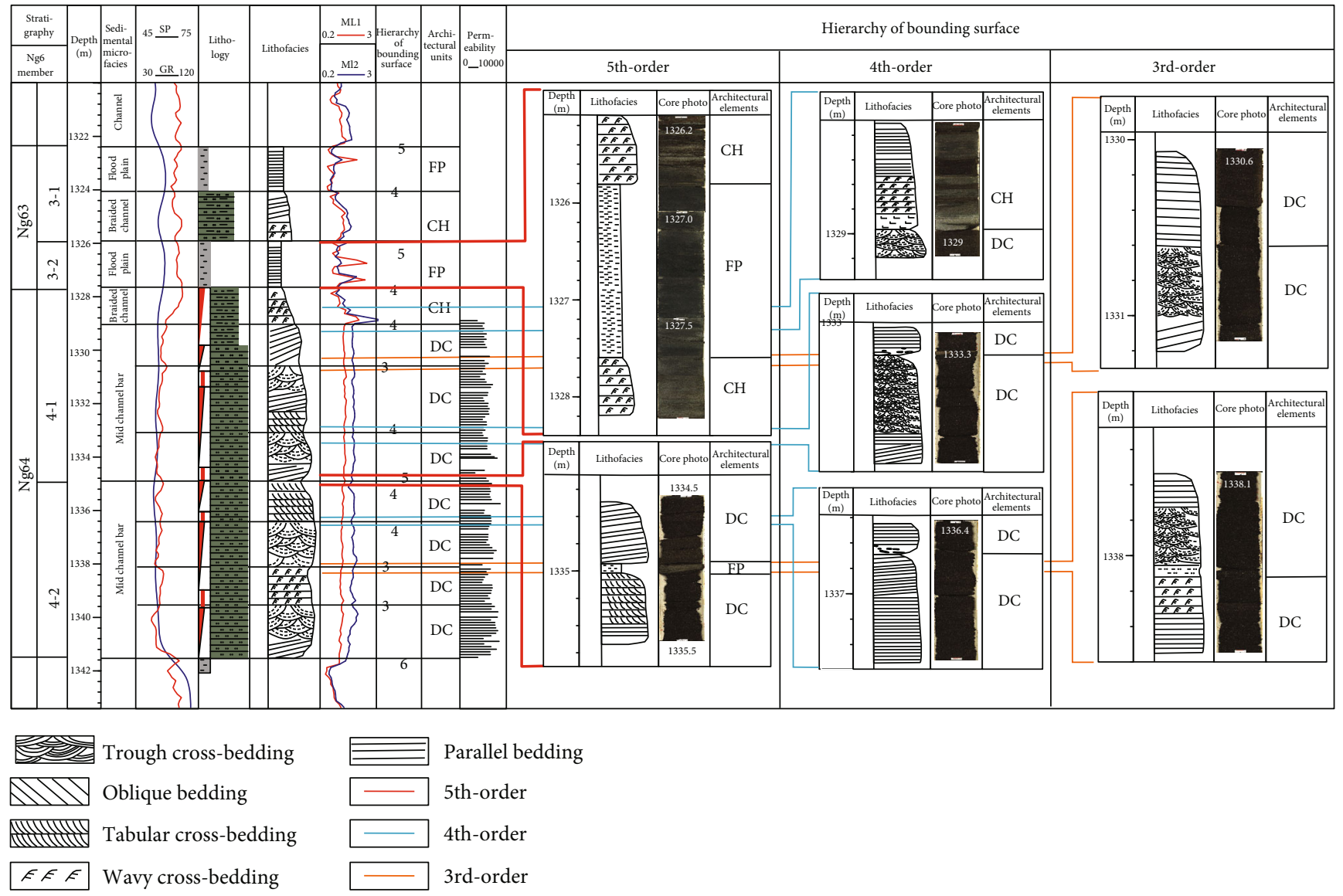

FIGURE 6: Lithological characteristics of hierarchical bounding surfaces. FP: flood plain; CH: channel; DC: channel dam.

mudstone), the SP and COND curves show a bell-like shape with a thickness of 3-6 m, the curve value ranging from the bottom to the top is weak, and the proportion is approximately $20 \%$. In the compound bell type, a high overall amplitude curve and a large thickness are shown by a group of bellshaped combinations with a thickness of 7 12 m, which accounts for approximately $5.3 \%$. In the compound round type, fine sandstone-siltstone and pebbly sandstone can be found in the top and bottom parts. The overall amplitude of the curve is high, the thickness of the sand body is large, the upper part is bell-shaped, the lower part is funnel-shaped, thereby corresponding to the compound rhythm, and the thickness is $6 \sim 11 \mathrm{~m}$, which accounts for approximately $2.8 \%$ of all types. Compared with the bell-shaped type, the funnel type has a larger upward curve; furthermore, the upper part is fine-grained sandstone, and the bottom is pebbly sandstone. The curve shows a funnel-like shape and a thickness of $4 \sim 7 \mathrm{~m}$, which accounts for $1.7 \%$ of all diagram types.

The braided filling channel comes in four types: sand, sand mixed with thin mud, sand at the bottom and mud at the top, and mud filling. In the sand filling type, the SP and COND curves show bell-shaped features; the logging range is high but weaker than that of the midchannel bar. The thickness is $2 \sim 5 \mathrm{~m}$. This type accounts for $38.2 \%$ of the total channel filling. In the sand mixed with thin mud filling type, the curve is toothed bell-shaped, the thickness is approxi- mately $3 \sim 5 \mathrm{~m}$, and the proportion is $14.5 \%$. In the sand at the bottom and mud at the top filling type, the curve is low bell-shaped, and the top amplitude is low. In this type, the thickness is $2 \sim 5 \mathrm{~m}$, which accounts for $19.5 \%$ of the total. The curve of mud filling is not an apparent finger or lowtooth profile, the amplitude is low, the thickness is $1 \sim 3 \mathrm{~m}$, and the proportion is $27.8 \%$ of the filling channels.

4.3. Hierarchical Bounding Surface Identification. A hierarchical architectural interface has a certain sedimentologic significance that reflects the heterogeneity of reservoirs in different scales and has several identification marks in core and logging data. Miall's classification method of architectural elements and hierarchical bounding surfaces is used for the sandy braided river. The 5th-order surfaces are defined as the surfaces of the braided river. The 4thorder surfaces are defined as the surfaces of braided filling channels or midchannel bars. The 3rd-order surfaces are defined as the surfaces of accretions in midchannel bars (Figure 6).

A one-to-one correspondence is observed between architectural bounding surfaces and architectural elements, and the 5th-order bounding surface is the boundary of the single-braided river. Stabilized floodplain mudstone deposits generally exist in the braided river at different periods. Thus, the floodplain is an important symbol for judging the 5thorder bounding surface, reflected by the logging curve. The 


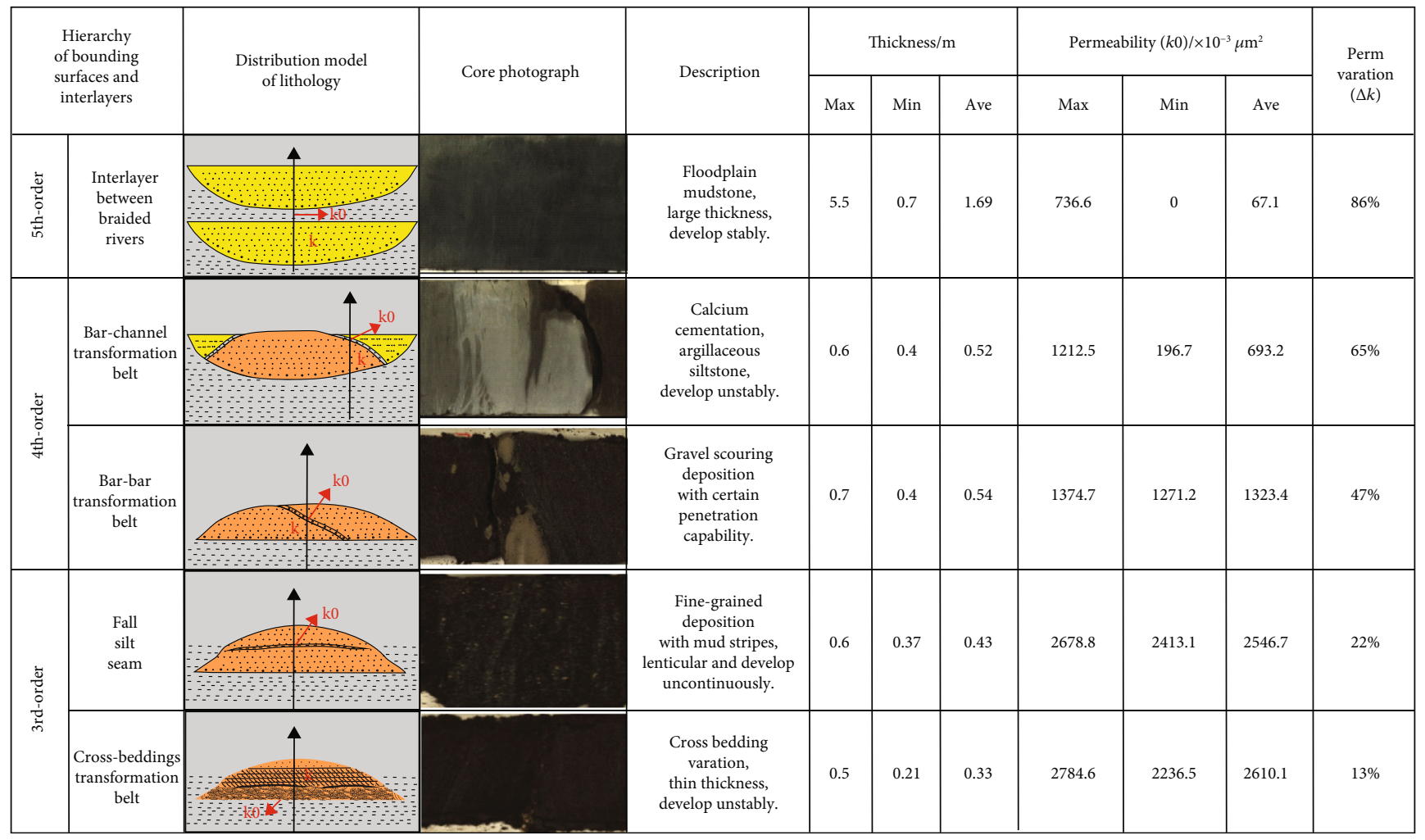

FIgURE 7: Depositional model and physical properties characteristics of hierarchical bounding surfaces.

SP curve shows a clear baseline segment, and the ML logging curve also has noticeable returns.

The 4th-order architectural bounding surface is the boundary of the single midchannel bar or braided filling channel sediments. Midchannel bars are usually deposited in the middle of the river because of the special bidirectional circulation of braided rivers, with the hydrodynamic flow weakening in the later period, the gullies on two sides of the midchannel bar eventually filled with sandy or muddy sediments, which are called braided filling channel sediments. The symbols for judging the 4th-order architectural bounding surface are the connected interfaces of midchannel bars and braided filling channel sediments called bar-channel transformation interfaces. However, midchannel bars may migrate laterally or the braided filling channel sediments may be completely scoured by a subsequent river. A midchannel bar may directly be adjacent to the latter midchannel bar. This kind of 4th-order architectural bounding surface is called a bar-bar transformation interface. Fine-grained argillaceous siltstones usually exist at the bar-channel interface, with calcium cementation. The SP curve eventually shows a noticeable return. Meanwhile, the ML logging curve has noticeably high values due to calcium cementation deposition. The SP and ML wireline logs are reflected as relatively slight returns because the bar-bar interface generally has gravel-scoured erosion sediments deposited at the bottom of the latter midchannel bars.

The 3rd-order architectural bounding surface is the boundary of the single accretion. The end of one accretion and the start of the next generally reflect the direction and strength changes of the hydrodynamic circumstance. Two types of interfaces are found between the two accretions. The first interface is a thin muddy siltstone deposition, with an increased clay content weakened hydrodynamic. The second interface comprises sedimentary bedding structures that reflect changes in hydrodynamic conditions. The 3rd-order architectural bounding surface has a small effect on reservoir heterogeneity, and the amplitude that responds on logging carves is also relatively weak. The responding difference on the SP logging is too weak to identify the 3rd-order architectural bounding surface and is frequently accompanied by a slight return of the GR and ML curves.

In general, senior interfaces limit the deposition of junior interfaces. Thus, the architectural interface analysis is hierarchical. The 4th-order interface is analyzed in the 5th-order interface, and the 3th-order interface is analyzed in the 4thorder interface. However, the interface usually records an erosion event for fluvial deposits. That is, the sediments of a new period cut through and erode the sediments of an old period. Thus, the analysis of the hierarchical interface of underground braided river reservoirs is based on the characteristics of cutting and erosional channels. For example, if the top surface of a midchannel bar is a 4th-order interface, then the bottom surface is generally recognized as a 5th-order interface located in a braided river.

\section{Discussion}

5.1. Genetic Mechanism of Hierarchical Bounding Surfaces. Different hierarchical architectural interfaces have different lithological characteristics, which, in turn, represent different genetic depositional mechanisms. Meanwhile, architectural 


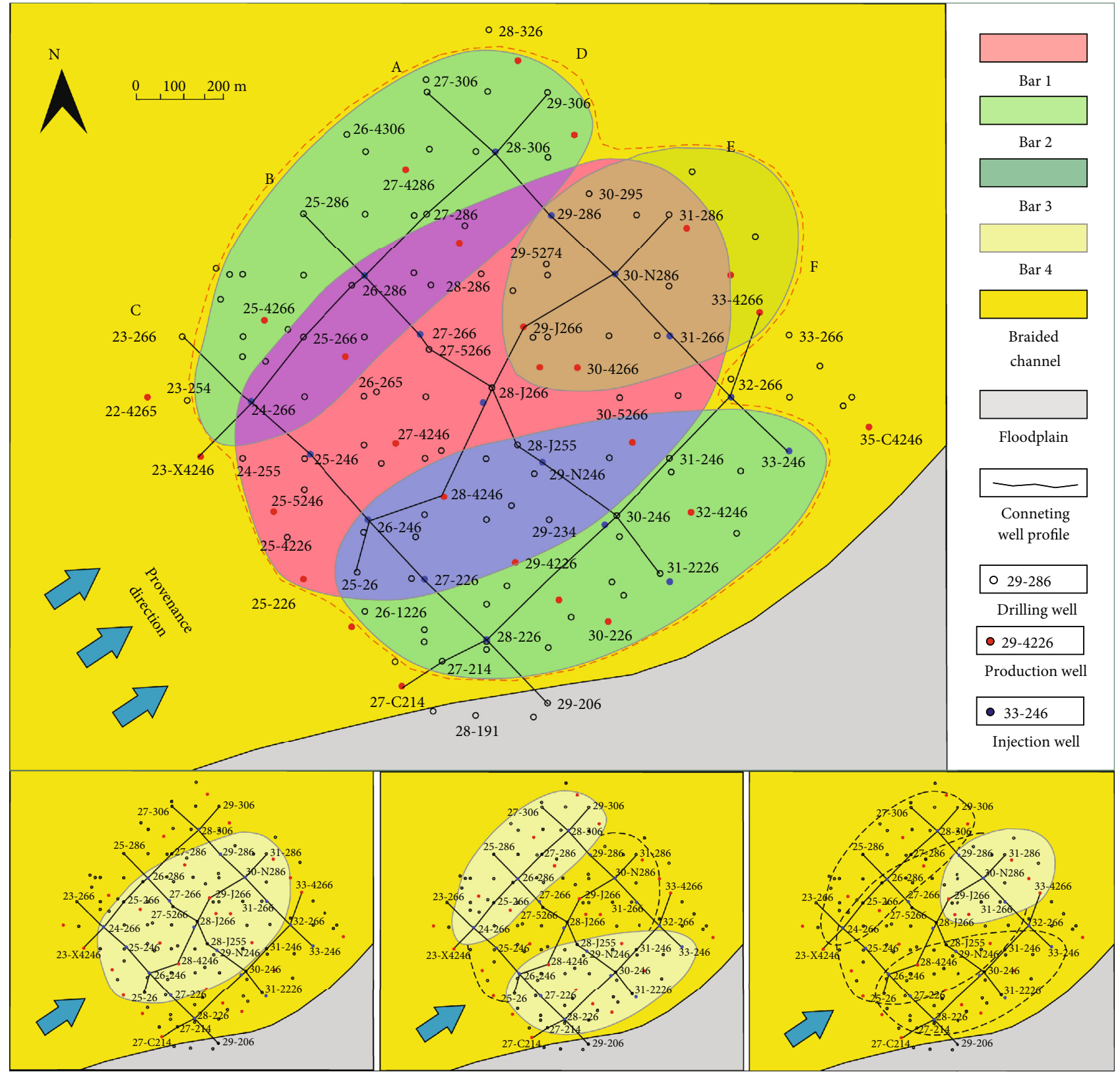

Figure 8: Planar distribution of single midchannel bar.

interfaces have different effects on reservoir quality and heterogeneity. An interface is considered a physical boundary. We select three parameters for investigating their effects on reservoir heterogeneity (Figure 7). The first parameter, which is called $k 0$, is the interlayer's porosity and permeability between two architectural elements. The second parameter, which is called $k$, is the porosity and permeability of architectural elements. The third parameter, which is called $\Delta k$, is the variation of permeability on the two sides of the interface and represents the rate of change in permeability, which is expressed as $\Delta k=(k-k 0) / k$.

The floodplain mudstones among the 5th-order interfaces are generally deposited in the intermittent period of the river. The hydrodynamics is weak, and the mudstones develop stably with a large thickness and a wide range [30]. The maximum, minimum, and average thicknesses are 5.5, 0.7 , and $1.69 \mathrm{~m}$, respectively. Floodplain mudstones with extremely small porosity and permeability cannot effectively store and transport fluid; the maximum, minimum, and average $k 0$ is $736.6,0$, and $67.1 \times 10^{-3} \mu \mathrm{m}^{2}$, respectively, and $\Delta k$ is comparatively large.

An interlayer that is different from the architectural elements exists among the 4th-order hierarchical interfaces. The interlayer among the bar-channel interfaces is in the middle of the midchannel bar and the braided filling channel sediments. The interlayer is usually a fine-grained interlayer or argillaceous siltstone with poor petrophysical properties and calcium cementation. At the end of the midchannel bar 


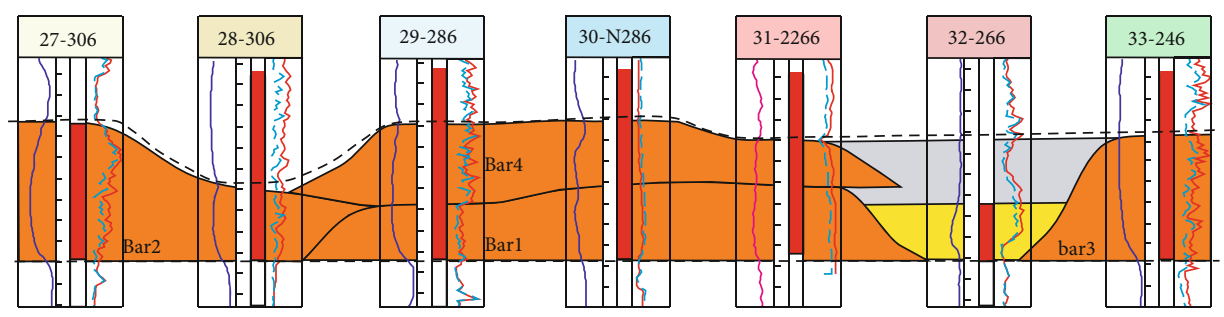

(a)

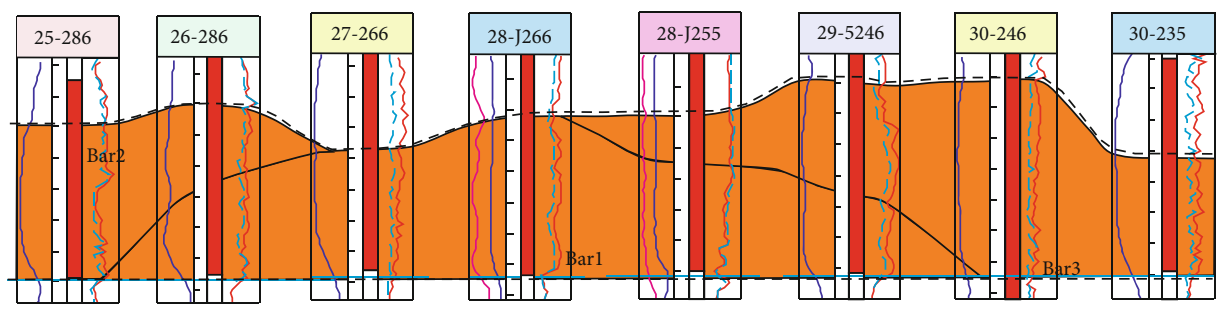

(b)

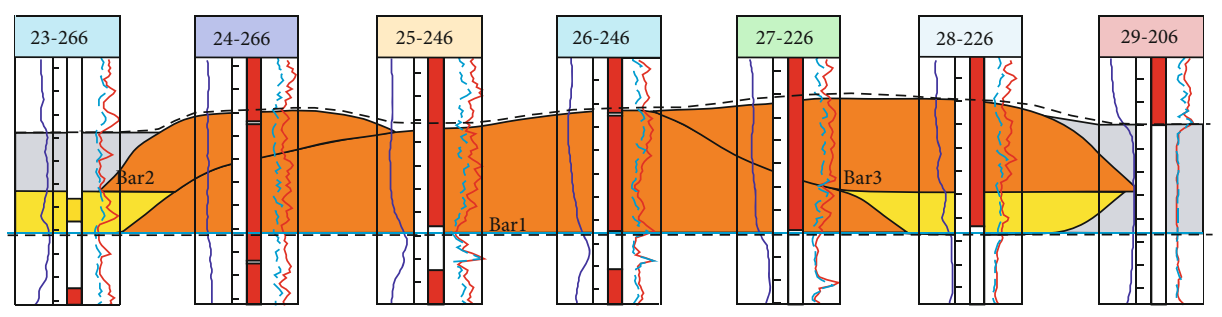

(c)

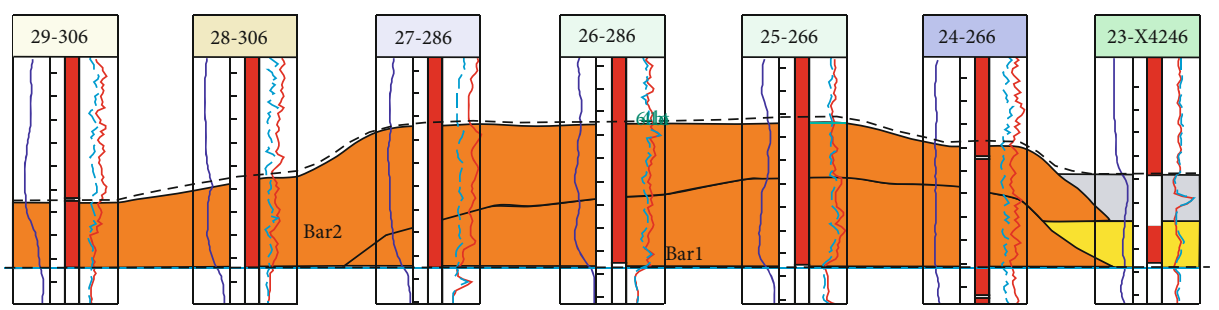

(d)

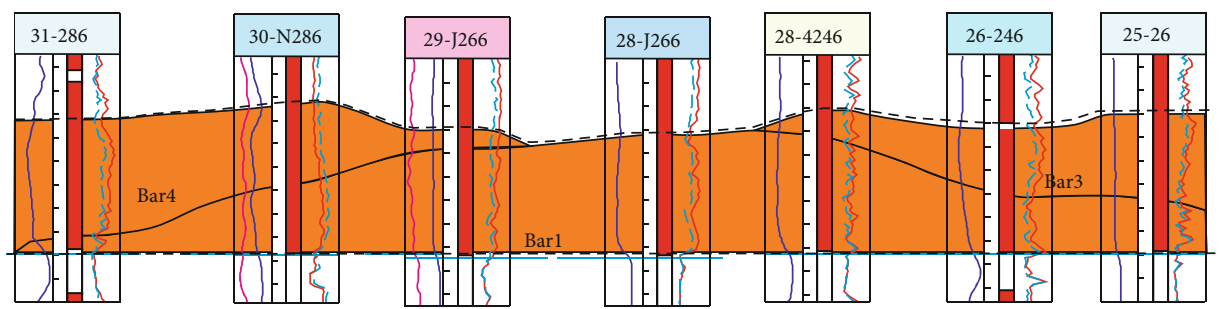

(e)

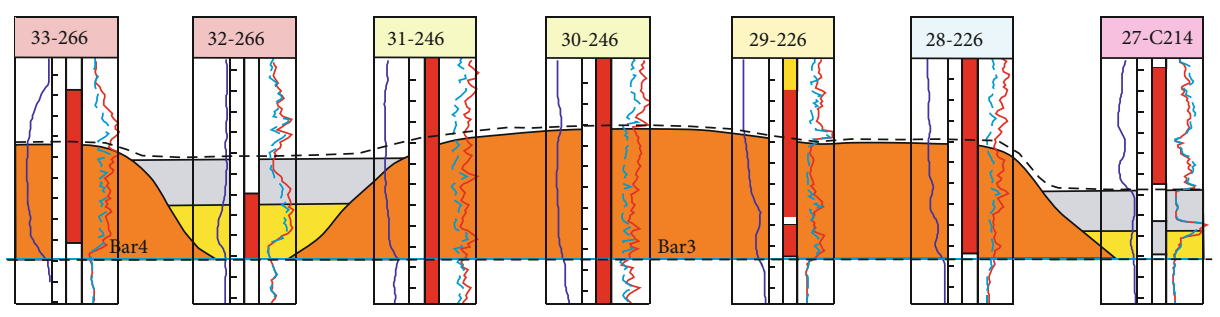

(f)

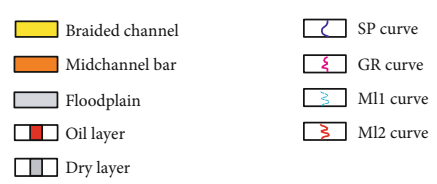

FIGURE 9: Identification profiles of single midchannel bar. 

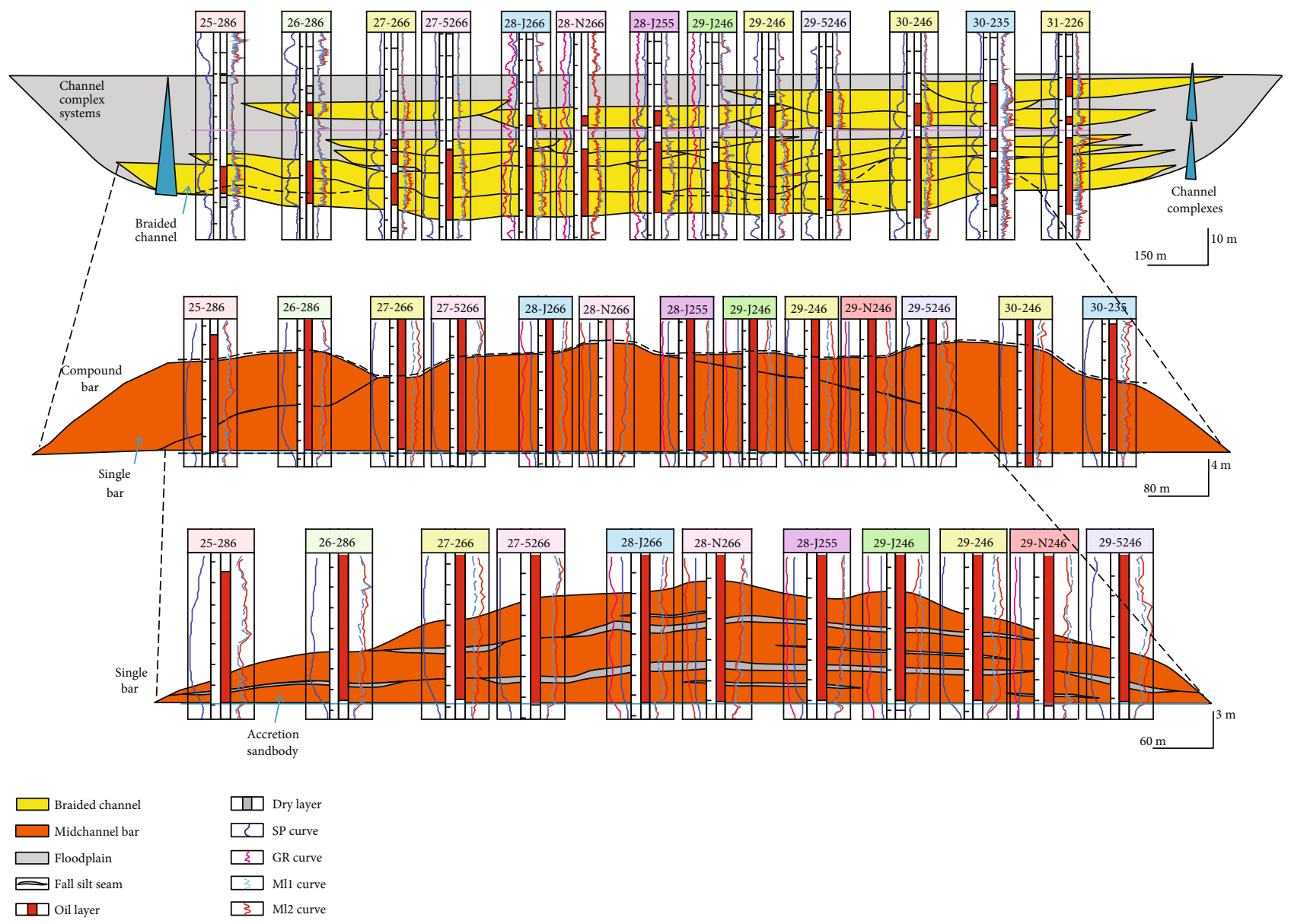

FIGURE 10: Identification profiles of different orders of architectural unit.

deposition, the hydrodynamics on the two sides of the bar is weakened, thus, gradually filling the fine-grained sediments. The maximum, minimum, and average thicknesses of the interlayer among the bar-channel interfaces are 0.6, 0.4, and $0.52 \mathrm{~m}$, respectively.

Meanwhile, fine-grained sediments have a certain penetrability; the maximum, minimum, and average $k 0$ is 1212.5 , 196.7, and $693.2 \times 10^{-3} \mu \mathrm{m}^{2}$, respectively, and $\Delta k$ is large but smaller than that of the 5th-order interfaces. Second, the interlayer among the bar-bar interfaces is in the middle of two midchannel bars. However, several differences are found in sedimentation due to the differences in hydrodynamic circumstances between the two bars. The interlayer among the bar-bar interfaces frequently has gravel-eroded sediments that affect the petrophysical properties and heterogeneity of the reservoir. The maximum, minimum, and average thicknesses of the interlayer are $0.7,0.4$, and $0.54 \mathrm{~m}$, respectively. The maximum, minimum, and average $k 0$ is $1374.7,1271.2$, and $1323.4 \times 10^{-3} \mu \mathrm{m}^{2}$, respectively, and $\Delta k$ is comparatively small.

The interlayer among the 3rd-order hierarchical interfaces (or between two stages of accretion) is commonly recognized as the fall silt seam or trench. The interlayer is thin-layered muddy stripes, thin, and generally poor continuity. The maximum, minimum, and average thicknesses of the interlayer are $0.6,0.37$, and $0.43 \mathrm{~m}$, respectively. The maximum, minimum, and average $k 0$ is $2678.8,2413.1$, and $2546.7 \times 10^{-3} \mu \mathrm{m}^{2}$, respectively, and $\Delta k$ is comparatively small. A 3rd-order interlayer with cross-bedding variation that reflects a slight change in hydrodynamics without muddy strips is found between two accretions. The thickness of the interlayer among the interfaces is relatively thin, thus indicating the short intermittent period of the two stages for hydrodynamic changes. The lithology of the sediments is mainly fine-grained muddy sandstones. The maximum, minimum, and average thicknesses of the interlayer are 0.5 , 0.21 , and $0.33 \mathrm{~m}$, respectively. The interlayer does not affect the petrophysical properties and heterogeneity. The maximum, minimum, and average $k 0$ is 2784.6,2236.5, and $2610.1 \times 10^{-3} \mu \mathrm{m}^{2}$, respectively, and the value of $\Delta k$ is invariant.

5.2. Compound Bar Interpretation. The paleocurrent of the sandy braided river in the west 7th block of the Gudong oil field is reconstructed by synthesizing the core, logging, and production performance data of the dense well pattern areas, using Miall's classification method of architectural elements and hierarchical bounding surfaces. The developmental characteristics of the braided river, single midchannel bar, and single accretion are analyzed quantitatively. The width and 
thickness of the braided river are ranging from 408 to $1296 \mathrm{~m}$, and from 2.9 to $11.7 \mathrm{~m}$, respectively. The width-tothickness ratio is from 110 to 167 . The width and thickness of the single midchannel bar are from 196 to $337 \mathrm{~m}$ and from 4.0 to $7.3 \mathrm{~m}$, respectively. The width-to-thickness ratio is 38 51. The thickness of the single accretion is $1.0-1.5 \mathrm{~m}$. The paleocurrent is reconstructed by dividing the compound midchannel bar into single midchannel bars. Sand body deposits with multiperiod single midchannel bars are then superimposed to form a compound bar.

In the thick Sixth Member sandstone of the Guantao Formation in the west 7th block in Gudong oil field, for example, according to the braided filling channel sand bodies among the different bars, the different thicknesses of adjacent bars, different changes in sedimentary rhythm, unmatched interlayers in different bars, and different logging curve characteristics and dynamic data reveal disconnected signs and identify single bars. We identified four single midchannel bars (Figures 8 and 9) and divided them into two different depositional types, simultaneously with different position types and the same layers at different times. In Figure 8, the 1st-, 2nd-, and 3rd-time depositions are bars 1, 2, 3, and 4, respectively. Bars 1 and 2 belong to the depositional type at the same time but in different positions, while bars 2 and 3 belong to the depositional type with the same layer but at different times. A total of 1 fluvial system (7th-order), 2 compound braided rivers (6th-order), 11 braided rivers (5thorder), 41 midchannel bars (4th-order), and 96 accretions (3rd-order) are developed in the study area (Figure 10).

\section{Conclusions}

In this paper, the architecture interface and architecture units were identified using wireline logs, based on the understanding of the sedimentary environment and sedimentary characteristics. And the characteristics of different architecture units are further analyzed combined with wireline logs' shape and core photos. The following conclusions were obtained:

(1) The Guan $6^{3+4}$ layer of the study area is mainly typical sandy braided river deposits. The braided river deposits can be subdivided into the braided filling channel, midchannel bar, and floodplain microfacies

(2) Sand body deposits with multiperiod single midchannel bars are superimposed to form a compound bar. Four single midchannel bars were identified and then divided into two different depositional types, simultaneously with different position types and the same layers at different times

(3) The interlayer between two braided rivers is floodplain mud deposition, with poor physical properties, stable thickness, and strong blocking capacity. The interlayer between the braided filling channel and the midchannel bar is generally fine-grained sediments with calcium cementation and poor physical properties. The interlayer, between two midchannel bars, is a transformation belt and generally composed of gravel-scoured deposition with penetration capability.

\section{Data Availability}

All data can be obtained from the corresponding authors.

\section{Conflicts of Interest}

The authors declare that they have no conflicts of interest.

\section{Acknowledgments}

This work was supported by the Open Fund of Key Laboratory of Exploration Technologies for Oil and Gas Resources (Yangtze University), Ministry of Education (No. K202112), Open Foundation of Top Disciplines in Yangtze University (No. 2019KFJJ0818002), the National Natural Science Foundation of China (No. 41872129), and the National Science and Technology Major Project of China (Nos. 2016ZX05010001 and 2016ZX05011001).

\section{References}

[1] J. R. L. Allen, "Studies in fluviatile sedimentation: bars, barcomplexes and sandstone sheets (low-sinuosity braided streams) in the Brownstones (L. Devonian), Welsh Borders," Sedimentary Geology, vol. 33, no. 4, pp. 237-293, 1983.

[2] J. S. Bridge, "Rivers and floodplains: forms, process, and sedimentary record," Australian Geographical Studies, vol. 48, no. 3, pp. 386-387, 2003.

[3] S. A. Cain and N. P. Mountney, "Spatial and temporal evolution of a terminal fluvial fan system: the Permian Organ Rock Formation, South-east Utah, USA," Sedimentology, vol. 56, pp. 1774-1800, 2010.

[4] J. S. Bridge and R. S. Tye, "Interpreting the dimensions of ancient fluvial channel bars, channels, and channel belts from wireline-logs and cores," American Association of Petroleum Geologists, Bulletin, vol. 84, pp. 1205-1228, 2000.

[5] A. Xu, L. Mu, and Y. Qiu, "Distribution pattern of OOIP and remaining mobile oil in different types of sedimentary reservoir of China," Petroleum Exploration and Development, vol. 5, pp. 12-13, 1998.

[6] J. Liu, Q. Shu, B. Zhang et al., "Research and application of reservoir structure in thick oil layers of fluvial facies in Gudao Oilfield," Petroleum Geology and Recovery Efficiency, vol. 6, pp. 1-4, 2007.

[7] X. Wang, J. Hou, S. Song et al., "Combining pressurecontrolled porosimetry and rate-controlled porosimetry to investigate the fractal characteristics of full-range pores in tight oil reservoirs," Journal of Petroleum Science and Engineering, vol. 171, pp. 353-361, 2018.

[8] X. Wang, Y. Liu, J. Hou et al., "The relationship between synsedimentary fault activity and reservoir quality - a case study of the Ek1 formation in the Wang Guantun area, China," Interpretation, vol. 8, no. 3, pp. sm15-sm24, 2020.

[9] Z. Xu, C. Shen, and Y. Chen, "Architecture characterization for sandy braided river reservoir and controlling factors remaining oil distribution-a case study of P oilfield (Neogene), Bohai offshore, China," Acta Sedimentologica Sinica, vol. 34, pp. 5385, 2016. 
[10] Q. Chen, M. Zeng, F. Zhang, F. Leng, and H. Wei, "Identification of single channel in fluvial reservoir and its significane to the oilfield development," Petroleum Geology and Recovery Efficiency, vol. 11, pp. 13-15, 2004.

[11] B. Liao, W. Zhang, L. Li et al., "Study on modern deposit of a braided stream an facies model-taking the Yongding River as an example," Acta Sedimentologica Sinica, vol. 1, pp. 34-39, 1998.

[12] A. D. Miall, "Architecture and sequence stratigraphy of Pleistocene fluvial systems in the Malay Basin, based on seismic time-slice analysis," American Association of Petroleum Geologists, Bulletin, vol. 86, pp. 1201-1216, 2002.

[13] L. Colombera, N. P. Mountney, and W. D. McCaffrey, "A quantitative approach to fluvial facies models: methods and example results," Sedimentology, vol. 60, pp. 1526-1558, 2013.

[14] X. Yu, X. Ma, and L. Mu, Reservoir Geology Model and Analysis and Hierarchy Surface, Petroleum Industry Press, Beijing, 2004.

[15] D. L. Yue, S. H. Wu, H. Q. Tan, D. Y. Yu, X. Y. Jiang, and S. B. Liu, "An anatomy of paleochannel reservoir architecture of meandering river reservoir - a case study of Guantao formation, the west 7th block of Gudong oilfield," Earth Science Frontiers, vol. 15, no. 1, pp. 101-109, 2008.

[16] Z. Jin, Y. Yang, J. Shang, and L. Wang, "Sandbody architecture and quantitive paremeters of single channel sandbodies of braided river: cases from outcrops of braided river in Fukang, Liulin and Yanan areas," Natural Gas Geoscience, vol. 25, no. 3, pp. 311-317, 2014.

[17] B. Niu, X. Gao, Y. Zhao, and B. Song, "Architecture characterization and modeling of channel bar in paleo-braided river: a case study of dense well pattern area of Sazhong in Daqing oilfield," Acta Petrolei Sinica, vol. 1, pp. 89-100, 2015.

[18] A. J. H. Reesink and J. S. Bridge, "Influence of bedform superimposition and flow unsteadiness on the formation of cross strata in dunes and unit bars - Part 2, further experiments," Sedimentary Geology, vol. 222, no. 3-4, pp. 274-300, 2009.

[19] P. F. Williams and B. R. Rust, "The sedimentology of a braided river," Journal of Sedimentary Petrology, vol. 39, pp. 649-679, 1969.

[20] A. D. Miall, "Architectural-element analysis: a new method of facies analysis applied to fluvial deposits," Earth Science Reviews, vol. 22, no. 4, pp. 261-308, 1985.

[21] S. Roman and P. Nigel, "Interpreting complex fluvial and barform architecture: carboniferous Central Pennine Province, northern England," Sedimentology, vol. 63, pp. 207-252, 2016.

[22] G. L. Sheng, Y. L. Su, and W. D. Wang, "A new fractal approach for describing induced-fracture porosity/permeability/ compressibility in stimulated unconventional reservoirs," Journal of Petroleum Science and Engineering, vol. 179, pp. 855-866, 2019.

[23] G. L. Sheng, H. Zhao, Y. L. Su et al., "An analytical model to couple gas storage and transport capacity in organic matter with noncircular pores," Fuel, vol. 268, p. 117288, 2020.

[24] X. Shang, J. Hou, F. Sun et al., "Architectural characteristics and sedimentary models of beach-bar sandstone reservoirs: a case study of the Paleogene Shahejie Formation in Banqiao oilfield," Huanghua depression. Acta Petrolei Sinica, vol. 6, pp. 1160-1171, 2014.

[25] T. Sun, L. Mu, X. Wu et al., "A quantitative method for architectural characterization of sandy braided river reservoirs: tak- ing Hegli oilfield of Muglad Basin in Sudan as an example," Acta Petrolei Sinica, vol. 4, pp. 715-724, 2014.

[26] B. R. Gager, “The Tiger Formation: Paleogene fluvial sediments deposited adjacent to a deforming Cordilleran metamorphic core complex, northeastern Washington," Sedimentary Geology, vol. 38, no. 1-4, pp. 393-420, 1984.

[27] C. R. Hallsworth and J. I. Chisholm, "Provenance of late carboniferous sandstones in the Pennine Basin (UK) from combined heavy mineral, garnet geochemistry and palaeocurrent studies," Sedimentary Geology, vol. 203, no. 3-4, pp. 196-212, 2008.

[28] M. Ghinassi, W. Nemec, M. Aldinucci, S. Nehyba, V. Özaksoy, and F. Fidolini, "Plan-form evolution of ancient meandering rivers reconstructed from longitudinal outcrop sections," Sedimentology, vol. 61, no. 4, pp. 952-977, 2014.

[29] X. X. Wang, J. G. Hou, S. H. Li et al., "Insight into the nanoscale pore structure of organic-rich shales in the Bakken Formation, USA," Journal of Petroleum Science and Engineering, vol. 191, p. 107182, 2020

[30] S. Rood, G. M. Samuelson, J. H. Braatne, C. R. Gourley, F. M. R. Hughes, and J. M. Mahoney, "Managing river flows to restore floodplain forests," Front Ecol Environ, vol. 3, no. 4, pp. 193-201, 2005. 